Der Rheumatismus. Stoffwechsel und degenerativer Rheumatismus Symposium, Bad Nauheim, 1964. Edited by V. R. Oтт (1965). Pp. 254, illus., index. Steinkopff, Darmstadt.

This symposium on metabolism and degenerative rheumatism was held at Bad Nauheim on April 24 to 26,1964 , and the collection of papers is now published under the editorship of Prof. Dr. V. R. Ott in volume 36 of "Der Rheumatismus". The great value of these papers is best judged by some random sampling. Thus, we learn from Meyer and his coworkers (New York) that chondroitin-6-sulphate and keratosulphate II are closely associated and that with increasing age they replace chondroitin-4sulphate in costal cartilage, a process which one expects to find in senility; yet, in a young man of 23 with Marfan's syndrome, whose rib-cartilage was obviously of the young variety without any evidence of degeneration or calcification, keratosulphate formed 65 per cent. of the total mucopolysaccharide content. Lenoch (Prague) discussed anomalies of phenylalanine and tyrosine metabolism which may give rise to albinism, phenylketonuria, tyrosinosis, collagen disease, and alcaptonuria. He referred to the work of Nishimura and co-workers, who found that patients with collagen diseases (disseminated lupus erythematosus, polyarteritis nodosa, scleroderma, dermatomyositis, rheumatic fever, rheumatoid arthritis) excreted 2,5-dihydroxyphenylpyruvic acid in the urine. Siblings and sufferers from other diseases did not excrete 2,5-DHPPA. Though these Japanese workers threw no light on the causation of these diseases, they seem to have swung the pendulum towards a metabolic factor by their ob-ผ servation that administration of $2 \mathrm{~g}$. tyrosine resulted $\vec{\circ}$ in increased output of 2,5-DHPPA and a worsening in the clinical state, and that, conversely, a diet very poor in tyrosine and phenylalanine was followed by⿳亠口冋 evidence of objective and subjective improvement in⿳亠丷厂 20 to 75 days. However, it is not clear how long one can continue with a diet which is both unpalat- $\omega$ able and deficient in essential amino-acids. Since $N$ alcaptonuria (ochronosis) happens to be a condition ${ }_{1}^{\circ}$ in which a known substance can cause damage indistinguishable from osteo-arthritis, it was bound ${ }^{\supset}$ to receive a good deal of attention. Ott ( $\mathrm{Bad}_{\vec{Z}}$ Nauheim) pointed out that clinically it could also simulate ankylosing spondylitis. In his paper, Lenoch, mentioned his compatriot Sitaj who, in theo 16 years ending 1962, collected 250 cases of alca -0 tonuria, i.e. over one-third of the world total reporr-ted by that date. Alcaptonuria is endemic in certaun villages in Slovakia where the incidence of endemico goitre is also high. These two conditions are noto as unrelated as might appear at first because both $\stackrel{\mathbb{Q}}{\stackrel{2}{2}}$ homogenistic acid and thyroxin are derived from $\overrightarrow{\vec{O}}$ tyrosine.

The examples quoted above should suffice to stimulate the desire of the specialist to possess this. publication of 254 pages. Every paper is followedo by its discussion, and the summaries are given ino German and French. (British contributors, alas, $\frac{0}{3}$ were conspicuous by their absence.) The format, paper, print, and illustrations are excellent; there are을 indices of authors and subject matter and a table of contents is provided.

David Preiskel

\title{
KENNEDY RESEARCH INSTITUTE OF RHEUMATOLOGY
}

Dr.D. L.Gardner, M.D., F.R.C.P.(Ed.), Senior Lecturer in Pathology at the University of Edinburgh, has beeno appointed first Director of the Kennedy Research Institute of Rheumatology in the Charing Cross Group at the West London Hospital. He will take up his duties on June 1, 1966. Dr. L. E. Glynn, M.D., F.R.C.P.,? remains as Scientific Adviser to the Institute. 